\title{
ĐÁNH GIÁ KẾT QUẢ PHẪU THUẬT TÁCH THÀNH ĐỘNG MẠCH CHỦ TYPE A TẠI BỆNH VIỆN TIM HÀ NỘI
}

Nguyễn Sinh Hiền*, Hà Đức Linh*

\section{TÓM TÁT}

Hồi cứu 43 hồ sơ bệnh nhân tách thành động mạch chủ $(\mathrm{DMC})$ type $\mathrm{A}$ được phẫu thuật tại Bệnh viện Tim Hà Nội từ $5 / 2015$ đến tháng 8/2017. 43 bệnh nhân vớituối trung bình là 54,7 \pm 15 , tỉ lệ nam/nữ $=2,6$. Có 7 bệnh nhân được chẩn đoán hội chứng Marfan (16,28\%). Các kỹ thuật phẫu thuật: thay đoạn ĐMC lên: 18 bệnh nhân $(41,86 \%)$, phẫu thuật Bentall: 13 bệnh nhân $(30,23 \%)$, thay quai ĐMC: 10 bệnh nhân $(23,26 \%)$, can thiệp vào hệ động mạch vành: 2 bệnh nhân $(4,65 \%)$. Thời gian chạy tuần hoàn ngoài cơ thể trung bình: $178,1 \pm 45,8$ phút ,thời gian clamp ĐMC trung bình: $126,4 \pm 24,9$ phút. Tỉ lệ tử vong sớm sau mổ 9,3\%. Có 4 bệnh nhân phải mổ lại do chảy máu và 1 mổ lại vì hở van ĐMC.

Tù khóa:tách thành động mạch chủ

SUMMARY

\section{Assessement of results of acute aorta dissection type A at Hanoi Heart Hospital.}

A retrospective study with 43 cases of acute aorta dissection type Aoperatedfrom 5/2015 to 8/2017 at Hanoi Heart Hospital. A total of 43 patients, mean age: $54,7 \pm 15$, male/female 2,6. 7 patients $(16,28 \%)$ of Marfan syndrome. Technique of operation: 18 patients of ascending aorta replacement $(41,86 \%), 13$ patients of Bentall procedure $(30,23 \%), 10$ patients of arch repair $(23,26 \%)$ and 2 operations on coronary system (4,65\%). Mean cardiopulmonary bypass time $178,1 \pm 45,8$ minutes, mean aortic clamp time $126,4 \pm 24,9$ minutes. The overall prevalence of inhospital death was 9,3\%. 4 reoprations for postoperative bleeding and 1 aortic valve regurgitation

Key words: acute aorta dissection.

\section{I. ĐẶT VẤN ĐỀ}

Tách thành ĐMC type $\mathrm{A}$ cấp tính là bệnh lý phức tạp, nặng nề. Việc chẩn đoán chính xác và điều trị kịp thời là rất cần thiết để cứu sống người bệnh. Nếu không được điều trị, tỉ lệ tử vong trong bệnh lý tách thành ĐMC type $\mathrm{A}$ cấp tính có thể lên tới $50 \%$ trong $48 \mathrm{~h}$ đầu tiên và tăng thêm $1 \%$ mỗi giờ, tử vong tới hơn $90 \%$ sau 1 năm [1][2].

Điều trị phẫu thuật là phương pháp hiệu quả nhất, làm giảm tỉ lệ tử vong xuống còn khoảng 10\%. Năm 1955, DeBakey thông báo ca phẫu thuật đầu tiên điều trị tách thành ĐMC. Từ đó đến nay, có nhiều nghiên cứu về bệnh lý này cũng như kết quả phẫu thuật từ các trung tâm tim mạch trên thế giới. Tại Việt Nam, điều trị phẫu thuật bệnh lý tách thành ĐMC type $\mathrm{A}$ cấp tính đã thực hiện đầu tiên tại Bệnh viện Việt Đức vào những năm 2000. Hiện nay, nhiều trung tâm phẫu thuật tim lớn trong nước đã triển khai thành công phẫu thuật này với kết quả ngày càng khả quan.

Bệnh viện Tim Hà Nội đã thực hiện phẫu thuật này từ nhiều năm nay và hiện nay số lượng phẫu thuật ngày càng nhiều. Chúng tôi thực hiện nghiên cứu này nhằm mục đích đánh giá kết quả sớm phẫu thuật điều trị tách thành ĐMC type $\mathrm{A}$ cấp tính tại bệnh viện Tim Hà Nội.

\section{II. ĐỐI TƯợNG VÀ PHƯƠNG PHÁP NGHIÊN CÚU}

Mô tả 43 trường hợp tách thành ĐMC type $\mathrm{A}$ cấp tính được phẫu thuật tại bệnh viện Tim Hà Nội từ tháng 5 năm 2015 đến tháng 8 năm 2017. Không đưa vào nghiên cứu những hồ sơ của bệnh

\footnotetext{
* Bệnh viện Tim Hà Nội

Người chịu trách nhiệm khoa hoc: Ts. Nguyễn Sinh Hiền Ngày nhận bài: 01/05/2018 - Ngày Cho Phép Đăng: 20/05/2018 Phản Biện Khoa học: GS.TS. Bùi Đức Phú PGS.TS. Đặng Ngoc Hùng
} 
nhân phẫu thuật tách thành ĐMC type $\mathrm{A}$ mãn tính, tách thành ĐMC type $\mathrm{B}$, phồng ĐMC...

Số liệu được xử lý bằng phần mềm SPSS 22.

\section{KẾT QUẢ}

\section{1. Đặc điểm bệnh nhân:}

Tuổi: Tuổi trung bình: 54,7 \pm 15 (13-78) tuổi;

Giới: Tỉ lệ nam/nữ = 2,6

Bảng 3.1: Tiền sử bệnh nhân

\begin{tabular}{|l|c|c|}
\hline Tiền sử & n & Tỷ lệ \% \\
\hline Marfan & 7 & $16,28 \%$ \\
\hline Tăng huyết áp & 32 & $74,42 \%$ \\
\hline Đã phẫu thuật tim hở & 3 & $6,98 \%$ \\
\hline
\end{tabular}

Bảng 3.2: Triệu chứng lâm sàng

\begin{tabular}{|l|c|c|}
\hline Triệu chứng & n & Tỷ lệ \% \\
\hline Đau ngực & 42 & $97,66 \%$ \\
\hline Tăng huyết áp & 30 & $69,77 \%$ \\
\hline Tai biến thần kinh & 2 & $4,65 \%$ \\
\hline Chèn ép tim cấp / Shock & 2 & $4,65 \%$ \\
\hline
\end{tabular}

\section{Bảng 3.3: Tổn thương giải phẫu}

\begin{tabular}{|l|l|l|}
\hline Tổn thương giải phẫu & $\mathbf{n}$ & Tỷ lệ \% \\
\hline Tách thành ĐMC & 36 & 85,71 \\
\hline máu tụ trong thành & 6 & 14,29 \\
\hline Hở van ĐMC nặng & 11 & 32,56 \\
\hline
\end{tabular}

\section{2. Điều trị và kết quả sớm sau mổ}

Bảng 3.4: Tuần hoàn ngoài cơ thể

\begin{tabular}{|l|l|c|c|}
\hline \multicolumn{2}{|c|}{ Tuần hoàn ngoài co thể } & n & $\begin{array}{c}\text { Tỷ lệ } \\
\%\end{array}$ \\
\hline \multirow{2}{*}{$\begin{array}{l}\text { Vị trí đặt } \\
\text { canuyl } \\
\text { động } \\
\text { mạch }\end{array}$} & Động mạch nách & 22 & 51,16 \\
\cline { 2 - 4 } & Động mạch đùi & 17 & 39,53 \\
\cline { 2 - 4 } $\begin{array}{l}\text { Dung dịng mạch nách + đùi } \\
\text { bảo vệ cơ } \\
\text { tim }\end{array}$ & 4 & 9,3 \\
\cline { 2 - 4 } & Máu ấm & 24 & 55,81 \\
\cline { 2 - 4 } & Xustodiol & 19 & 44,19 \\
\cline { 2 - 4 } & Nuôi dòng & 30 & 69,77 \\
\hline \multirow{2}{*}{$\begin{array}{l}\text { Bảo vệ } \\
\text { tạng }\end{array}$} & Hạ thân nhiệt & 25 & 58,14 \\
\cline { 2 - 4 } & $\begin{array}{l}\text { Ngừng tuần hoàn }+ \\
\text { tưới máu não chọn lọc }\end{array}$ & 17 & 40,48 \\
\hline
\end{tabular}

Bảng 3.5: Các phương pháp phẫu thuật

\begin{tabular}{|l|c|c|}
\hline \multicolumn{1}{|c|}{ Phương pháp phẫu thuật } & $\mathbf{n}$ & Tỷ lệ \% \\
\hline Thay đoạn ĐMC lên & 18 & 41,86 \\
\hline Bentall & 13 & 30,23 \\
\hline Thay ĐMC lên + cắm lại ĐMV & 2 & 4,65 \\
\hline $\begin{array}{l}\text { Thay ĐMC lên + 1 phần quai } \\
\text { ĐMC }\end{array}$ & 5 & 11,63 \\
\hline $\begin{array}{l}\text { Thay ĐMC lên + toàn bộ quai } \\
\text { ĐMC }\end{array}$ & 4 & 9,3 \\
\hline $\begin{array}{l}\text { Bentall + thay quai ĐMC } \\
\text { PMC }\end{array}$ & 1 & 2,33 \\
\hline
\end{tabular}

Thời gian thở máy trung bình: $3,7 \pm 3,5$ ngày

Thời gian nằm hồi sức trung bình: 7,5 $\pm 5,9$ ngày

Thời gian nằm viện trung bình: $19,7 \pm 10,2$ ngày

Bảng 3.6: Biến chứng mổ lại và tử vong sớm sau mổ

\begin{tabular}{|l|l|c|c|}
\hline \multicolumn{2}{|c|}{$\begin{array}{c}\text { Mổ lại, biến chứng, } \\
\text { tử vong }\end{array}$} & n & Tỷ lệ \% \\
\hline \multirow{2}{*}{ Mổ lại } & Chảy máu & 4 & $9,3 \%$ \\
\cline { 2 - 4 } & $\begin{array}{l}\text { Hở van } \\
\text { ĐMC }\end{array}$ & 1 & $2,32 \%$ \\
\hline \multirow{2}{*}{$\begin{array}{l}\text { Biến } \\
\text { chứng }\end{array}$} & Viêm phổi & 10 & $23,2 \%$ \\
\cline { 2 - 4 } & Tai biến não & 8 & $29,06 \%$ \\
\cline { 2 - 4 } & Suy đa tạng & 8 & $29,06 \%$ \\
\hline \multirow{2}{*}{ Tử vong } & Tai biến não & 2 & $4.64 \%$ \\
\cline { 2 - 4 } & Suy đa tạng & 2 & $4.64 \%$ \\
\hline
\end{tabular}

\section{BÀN LUẬN}

\section{1. Đặc điểm trước mổ}

\section{Tuổi, giới}

Tuổi trung bình trong nghiên cứu của chúng tôi là $54,7 \pm 15$ (tuổi), trong đó nhỏ nhất là 13 tuổi, lớn nhất là 78 tuổi. Nam giới chiếm $72,1 \%$. Trong nghiên cứu này, tỉ lệ bệnh nhân trẻ tuổi có hội chứng Marfan chiếm 16,28\% với độ tuổi trung bình là 30,14 tuổi.Hội chứng Marfan là rối loạn tồ chức mô liên kết có tính di truyền, phổ biến nhất với tần suất $1 / 10000$ trẻ ra đời sống. Biến chứng ĐMC (phồng vỡ, tách thành) do giãn gốc ĐMC là biến chứng nặng nhất của bệnh, phát triển rất nhanh ở độ tuổi thanh thiếu niên và là nguyên nhân gây tử 
vong hàng đầu của bệnh nhân Marfan dưới 40 tuổi nếu không được phẫu thuật kịp thời. Bệnh nhân Marfan chiếm tỉ lệ lớn với độ tuổi trung bình thấp đã làm cho độ tuổi trung bình chung của nghiên cứu thấp hơn so với các nghiên cứu khác [7][8].

\section{Đặc điểm lâm sàng và cận lâm sàng}

Trong nghiên cứu triệu chứng lâm sàng nổi bật và gặp nhiều nhất ở hầu hết bệnh nhân là đau ngực $(97,66 \%)$. Đau ngực trong tách thành ĐMC là do mạch máu bị giãn căng đột ngột, với cường độ mạnh và liên tục. Tỉ lệ bệnh nhân đến bệnh viện trong vòng 24 giờ từ khi đau ngực chiếm chưa tới $1 / 2$, nguyên nhân có thể là do quá trình chẩn đoán chưa kịp thời và chính xác. Xét nghiệm Troponin $\mathrm{T}$ hs tăng cao ở 55,5\% bệnh nhân, sự thay đổi trên điện tim cùng với dấu hiệu đau ngực không điển hình làm cho bệnh nhân dễ bị chẩn đoán nhầm với một cơn đau thắt ngực hoặc cơn nhồi máu cơ tim.

Tăng huyết áp cũng là 1 triệu chứng hay gặp, chiếm $69,77 \%$, tương đương với nghiên cứu của Hagan 69,3\% [8]. Tăng huyết áp là yếu tố nguy cơ cao của tách thành ĐMC type $\mathrm{A}$, đặc biệt là tăng huyết áp ác tính. Hầu hết bệnh nhân trong nghiên cứu đều không được điều trị kiểm soát tốt huyết áp.

Có 2 bệnh nhân vào viện trong tình trạng shock do chèn ép tim cấp. Đây là một trong những nguyên nhân chính gây tử vong ở các bệnh nhân tách thành ĐMC. Máu ngấm từ thành mạch của ĐMC bị tổn thương ra màng ngoài tim gây chèn ép tim, là dấu hiệu dọa vỡ ĐMC do đó cần can thiệp càng sớm càng tốt. 1 trong 2 bệnh nhân này phải làm phẫu thuật dẫn lưu dịch màng tim cấp cứu qua đường Marfan trước rồi mới mở ngực qua đường giữa xương ức. Ngoài ra phần lớn các bệnh nhân đều có tràn dịch màng tim tuy nhiên số lượng từ ít đến vừa không gây chèn ép tim.

Chụp cắt lớp vi tính (CLVT) được xem là tiêu chuẩn vàng để chẩn đoán xác định bệnh lý tách thành ĐMC. Kết quả chụp CLVT cũng là cơ sở để phân loại tách thành ĐMC type $\mathrm{A}$ theo Stanford hoặc theo Svensson. Sự phân chia type không thay đổi chỉ định phẫu thuật mà chủ yếu có giá trị tiên lương sau mổ và theo dõi xa. Trong nghiên cứu, hình ảnh chụp CLVT được phân loại theo 2 thể theo Svensson là thể kinh điển (36 trường hợp chiếm $85,71 \%)$ và thể máu tụ trong thành $(6$ trường hợp chiếm 14,29\%). Đặc biệt trong số 6 bệnh nhân thể máu tụ trong thành có 1 bệnh nhân bị tách thành ĐMC sau can thiệp (type 5 theo Svensson).

Mức độ hở van ĐMC cũng được đánh giá đầy đủ trên siêu âm tim: hở van ĐMC nhiều (4/4 và $3 / 4$ ) chiếm $32,56 \%$. Hầu hết các trường hợp hở van ĐMC không có tổn thương thực thể tại van. Ngoài các bệnh nhân Marfan có cơ chế hở van ĐMC là do giãn gốc ĐMC gây giãn vòng van, các trường hợp hở van còn lại có cơ chế do sa mép van do tổn thương tách thành ĐMC lan vào các xoang vành trong khi cấu trúc lá van vẫn bình thường. Vì thế có thể sửa chữa các thương tổn này bằng cách khâu cố định lại mép van vào thành ĐMC mà không cần can thiệp vào gốc ĐMC.

\section{2. Đặc điểm trong mổ}

Tất cả $43 \mathrm{BN}$ trong nghiên cứu đều được phẫu thuật với tuần hoàn ngoài cơ thể.Khi tiến hành phẫu thuật tách thành $\mathrm{ĐMC}$, vị trí thông thường đặt ống ĐM (ở ĐMC lên) gần như không thực hiện được, do đó các đường vào ngoại vi là lựa chọn bắt buộc. Có 2 vị trí ĐM được sử dụng là $\mathrm{ĐM}$ đùi và $\mathrm{ĐM}$ nách. $\mathrm{DM}$ đùi có ưu điểm là kích thước lớn đảm bảo tốt lưu lượng khi chạy tuần hoàn ngoài cơ thể, là đường bảo vệ tạng tầng bụng khi cần phẫu thuật vào vùng quai ĐMC, vị trí nông do đó kỹ thuật đặt rất nhanh chóng và dễ̂̃ dàng (hữu ích trong những trường hợp cấp cứu cần chạy tuần hoàn ngoài cơ thể ngay),tuy nhiên đặt ống ĐM vào ĐM đùi có nguy cơ làm tình trạng tổn thương mạch nặng hơn và có thể gây nên thiếu máu tạng do tưới máu ngược dòng vào lòng giả hoặc bong các mảng xơ vữa hoặc máu cục lên não trong trường hợp lỗ vào nằm ở sau ĐM dưới đòn trái, ĐMC xuống hoặc ĐMC bụng. Trong khi đó ĐM nách được ưu tiên lựa chọn hơn do các ưu điểm: thường tổn thương không lan đến vị trí ĐM nách, hướng bơm máu xuôi dòng tránh tình trạng tách thành tiến triển trong phẫu thuật, thuận lợi cho việc ngừng tuần hoàn và tưới máu não chọn lọc... Trong phẫu thuật tách thành 
ĐMC type A cấp tính, lựa chọn ĐM nách để bơm máu xuôi dòng, kèm theo hạ thân nhiệt vừa, ngừng tuần hoàn và tưới máu não xuôi dòng chọn lọc là phương án sinh lý nhất, ít gây tổn thương và rối loạn đông máu sau mổ. Trong trường hợp ngừng tuần hoàn có thể lựa chọn tưới máu não xuôi dòng hoặc ngược dòng, chọn lọc 1 bên hoặc 2 bên[4]. Theo tác giả Miralem Pasic, đặt canuyl ở ĐM nách làm giảm tỉ lệ tử vong so với ĐM đùi (5\% so với $20 \%)$, giảm tỉ lệ biến chứng thần kinh sau mổ (5\% so với $8 \%$ )[4]. Trong nghiên cứu, tỉ lệ đặt canuyl ĐM nách có 17 trường hợp, chiếm 39,53\%. Tỉ lệ đặt canuyl ĐM nách cao hơn ở giai đoạn sau của nghiên cứu. Tuy nhiên ĐM đùi cũng là lựa chọn cho những bệnh nhân nặng, tình trạng huyết động không ổn định do ưu điểm là đơn giản và dể thao tác. Trong nghiên cứu tỉ lệ đặt canuyl ĐM đùi là $51,16 \%$, nhiều hơn ở giai đoạn đầu của nghiên cứu. Ngoài ra có thể kết hợp đặt canuyl ở 2 vị trí $Đ M$ nách và $Đ M$ đùi, trong nghiên cứu chiếm 9,3\%. Lợi thế của đặt canuyl ĐM ở 2 vị trí là không phải ngừng tuần hoàn, không cần hạ nhiệt độ sâu để tránh các rối loạn đông máu mà vẫn can thiệp được vào vùng quai ĐMC.

Dung dịch liệt tim được bơm xuôi dòng ở 30 trường hợp $(69,77 \%)$ và ngược dòng ở 25 trường hợp $(58,14 \%)$, trong đó kết hợp cả 2 phương pháp xuôi và ngược dòng ở 12 trường hợp $(27,9 \%)$. Lý do chúng tôi sử dụng phương pháp liệt tim ngược dòng và kết hợp (thường lần đầu tiên là liệt tim xuôi dòng, các lần sau là liệt tim ngược dòng) vì phần gốc ĐMC chứa 2 lỗ ĐMV trong bệnh lý tách thành ĐMC type Athường bị tổn thương hoặc dễ tổn thương do đó chúng tôi không muốn tác động nhiều lần vào lỗ ĐMV[5].

Ngừng tuần hoàn kèm theo hạ nhiệt độ là phương pháp thường được sử dụng trong phâuu thuật. Việc phối hợp giữa ngừng tuần hoàn để bảo vệ các tạng, đặc biệt là não, và hạ thân nhiệt nhưng ko gây ra các rối loạn đông máu nặng sao cho hợp lý là rất cần thiết. Hạ thân nhiệt càng sâu thì các tạng càng được bảo vệ tốt, tuy nhiên sẽ kéo dài thời gian nâng và hạ nhiệt độ trong lúc mổ, đồng thời cũng gây ra các rối loạn đông máu, làm tăng thời gian phẫu thuật và tỉ lệ biến chứng sau mồ[6]. Trong nghiên cứu có 28 trường hợp có hạ thân nhiệt (chiếm $65,12 \%$ ) ở mức độ từ nhẹ đến vừa (từ $29^{\circ} \mathrm{C}$ đến $32^{\circ} \mathrm{C}$ ).

Ngừng tuần hoàn kèm theo tưới máu não chọn lọc không cần thiết phải thực hiện trên tất cả các bệnh nhân. Mục đích khi ngừng tuần hoàn là để đánh giá thương tổn ĐMC ở đoạn quai: lỗ vào, tách thành lan vào các nhánh ĐM nuôi não, ĐM dưới đòn, đoạn đầu ĐM chủ xuống. Ngừng tuần hoàn khi có chỉ định thay quai ĐMC, một phần quai ĐMC hoặc thay đoạn ĐMC lên với miệng nối xa theo kỹ thuật "open technique". Ngừng tuần hoàn luôn kèm theo với tưới máu não chọn lọc 1 bên hoặc 2 bên để bảo vệ não, và hạ nhiệt độ để bảo vệ các tạng phía dưới. Trong nghiên cứu có 17 trường hợp phải ngừng tuần hoàn, tất cả đều được tưới máu não chọn lọc xuôi dòng 2 bên $(40,48 \%)$. Không có sự liên quan giữa việc ngừng tuần hoàn, tưới máu não chọn lọc với các tai biến não trong quá trình hồi sức sau mổ[6]. Trong nghiên cứu này, chúng tôi sử dụng phương pháp bảo vệ não xuôi dòng 2 bên khi phẫu thuật vào vùng quai ĐMC (thay quai hoặc một phần quai ĐMC) hoặc kỹ thuật mở (open technique) khi làm miệng nối đầu xa.

Về cách thức làm miệng nối, sau khi đã cắt hết đoạn mạch bệnh lý đến tổ chức lành, chúng tôi sử dụng kỹ thuật bánh kẹp (sandwich) với 2 dải đệm (bằng mạch nhân tạo) bọc mặt trong và ngoài ĐMC để gia cố miệng nối trước khi khâu với đoạn mạch nhân tạo. Với những miệng nối nhỏ (gốc $Đ M$ vành), thay vì sử dụng dải đệm bằng mạch nhân tạo, chúng tôi sử dụng dải màng tim của bệnh nhân để gia cố miệng nối.

\subsection{Kết quả sớm sau mổ}

\section{Biến chúng sớm sau mổ}

Biến chứng hay gặp nhất trong nghiên cứu của chúng tôi là viêm phổi $(23,26 \%)$, tai biến mạch não và suy đa tạng chiếm tỷ lệ ngang nhau $(18,6 \%)$. Chảy máu phải mổ lại có 4 trường hợp $(9,3 \%)$ do chảy nhiều máu không cầm hoặc rối loạn đông máu nặng, ngoài ra cũng có nhiều trường hợp chảy máu sau mổ nhưng đều có thể điều trị nội khoa được. Trong nghiên cứu của tác giả Nguyễn Hữu Ước cũng cho biết chảy máu là 
biến chứng hay gặp nhất sau mổ tách thành ĐMC[1]. Tỷ lệ chảy máu mổ lại trong nghiên cứu của Nguyễn Thái An là 12,5\%[3]. Tuy nhiên, trong nghiên cứu của chúng tôi không có $\mathrm{BN}$ nào tử vong do chảy máu. Có 1 bệnh nhân phải mổ lại do hở van ĐMC. Bệnh nhân được phẫu thuật sửa van ĐMC, thay đoạn ĐMC lên tuy nhiên sau mổ còn hở van ĐMC nhiều được mổ lại sửa van ĐMC sau 2 tuần.

Tỷ lệ tai biến mạch máu não (TBMMN) gặp $18,6 \%$, chủ yếu là thể nhồi máu. $2 / 8$ bệnh nhân tử vong do tai biến mạch máu não, $1 \mathrm{BN}$ nhồi máu tiểu não mức độ ít, sau quá trình điều trị chỉ còn loạn thần nhẹ, $5 \mathrm{BN}$ nhồi máu nảo rải rác 2 bán cầu cũng không để lại di chứng khi ra viện. Tỷ lệ tai biến mạch não trong nghiên cứu của chúng tôi còn cao so với các tác giả trong và ngoài nước. Tác giả Nguyễn Thái An cho biết tỷ lệ biến chứng thần kinh vĩnh viễn trong nghiên cứu của mình là $4,2 \%$.

\section{Tử vong sớm sau mổ}

Không có $\mathrm{BN}$ nào tử vong trên bàn mổ do chảy máu hay suy tim cấp sau ngừng máy tim phổi nhân tạo.Trong nghiên cứu, có 4 bệnh nhân tử vong tại viện (nặng xin về) với tỉ lệ là 9,3\%. Trong đó có 2 bệnh nhân tử vong do tai biến não, 2 bệnh nhân tử vong do suy đa tạng không hồi phục. Tỉ lệ này thấp hơn so với nghiên cứu của Hagan $(26 \%)$ và với Nguyễn Thái An $(11,1 \%)$. 4 trường hợp tử vongđều được phẫu thuật thay quai ĐMC (toàn bộ hoặc một phần)do đó rất dễ tổn thương các ĐM nuôi não và thời gian phẫu thuật kéo dài gây nên suy đa phủ tạng. Trong nghiên cứu của Nguyễn Hữu Ước, tử vong chiếm $20,8 \%$ với nguyên nhân chính là suy tim cấp sau mổ và suy đa tạng [1].

Qua theo dõi xa sau 2 năm có 4 bệnh nhân tử vong, 1 bệnh nhân tử vong sau 1 năm do tách thành ĐMC type $\mathrm{B}$ tiến triển, 1 bệnh nhân tử vong sau 2 tháng ở bệnh viện khác do $\mathrm{u}$ đại tràng. 2 bệnh nhân tử vong tại nhà không rõ nguyên nhân.

\section{KẾT LUẬN}

Phẫu thuật điều trị bệnh lý tách thành động mạch chủtype Alà phẫu thuật nặng với tỷ lệ biến chứng và tử vong cao. Bệnh viện Tim Hà nội mới triển khai nhiều những phẫu thuật này trong vòng 3 năm trở lại đây. Tuy nhiên kết quả phẫu thuật rất khả quan với tỷ lệ tử vong $9,3 \%$.

\section{TÀI LIỆU THAM KHẢO}

1. Vũ Ngọc Tú, Nguyễn Hữu Ước (2013). Đánh giá kết quả phẫu thuật lóc động mạch chủ type A tại Bệnh viện Việt Đức. Tạp chí phẫu thuật Tim mạch và Lồng ngực Việt Nam, 4, 59-65.

2. Nguyễn Công Hựu, Đoàn Quốc Hưng, Dương Đức Hùng và cộng sự (2010). Kết quả phẫu thuật bệnh lý động mạch chủ ngực tại Bệnh viện Việt Đức. Hội nghị quốc tế Việt - Đức - những tiến bộ trong phẫu thuật và can thiệp tim mạch, 24-31.

3. Nguyễn Thái An và Phạm Thọ Tuấn Anh (2010). Đánh giá kết quả sớm phẫu thuật phình và bóc tách động mạch chủ lên và quai. Tạp chí Y học Việt nam, 375, 77-82.

4. Miralem P., S. J, B. M và cộng sự (2003). Canulation of the right axillary artery for surgery of acute type A aortic dissection. Eur J Cardiothorac Surg, 24, 231-236.

5. Allen H. J. BS, Hanafy H. J (1995). Retrograde cardiople-gia does not adequately perfuse the right ventricle. Thorac Cardiovasc Surg, 109(1116-1124),

6. Svensson L. G. (2008). Perfusion strategies for brain protection: rationale for a selective approach. Aortic Arch Surgery: Principles, Strategies and Outcomes, Blackwell Publishing Ltd, 177-186.

7. Eric M Siegal (2006). Acute aortic dissection. Journal of hospital medicine 94-105.

8. Hagan PG, Nienaber CA, Isselbacher EM et al. (2000)The International Registry of Acute Aortic Dissection (IRAD): new insights into an old disease. JAMA 283:879-903. 